\title{
High-resolution dielectric profiling of ice cores
}

\author{
J. C. MOORE \\ British Antarctic Survey, Natural Environment Research Council, Madingley Road, Cambridge CB3 OET, England
}

\begin{abstract}
A new method for high-resolution ( $3 \mathrm{~mm}$ ) dielectric profiling of ice cores is described. The method measures the capacitance and conductance of the ice at a single frequency (chosen to be $50 \mathrm{kHz}$ in this case). The technique requires only a few minutes per metre of core, and no sophisticated data analysis. The system is designed to operate on ice cores that have been cut longitudinally, providing one flat and one curved surface. The $50 \mathrm{kHz}$ conductance is dependent on the acid and neutral-salt concentrations in the ice. The new method was tested successfully on the GRIP core from Summit, Greenland, in 1991. It is useful for detecting seasonal variations in impurities in both acidic Holocene ice and in normally alkaline Wisconsin ice.
\end{abstract}

\section{INTRODUCTION}

The GRIP Greenland ice-core drilling project was designed to retrieve an ice core to bedrock from the summit of Greenland (about $3.1 \mathrm{~km}$ in length). The annual-layer thickness ranges from around $20 \mathrm{~cm}$ near the surface to about $2 \mathrm{~cm}$ at $2 \mathrm{~km}$ depth. The top $1625 \mathrm{~m}$ of core was made up of acidic ice from the current interglacial Holocene period. The core from below this to the depth reached at the end of the 1991 season $(2321 \mathrm{~m})$ contained generally alkaline, dusty ice from the cold climatic Wisconsin period.

Moore and Paren (1987) described the dielectric profiling (DEP) system for measuring the dielectric parameters of ice cores. The DEP system involves measuring the capacitance and conductance of the ice at a range of frequencies spanning the main Debye dielectric relaxation dispersion of ice. The capacitance of the ice is a measure of the real part (relative permittivity) of the complex permittivity of ice, whereas the conductance depends on the imaginary part or dielectric loss factor. At frequencies well below the Debye relaxation frequency, ice has a large relative permittivity of about 90 and the conductivity is essentially the d.c. value. The relative permittivity and conductivity change rapidly at frequencies near the relaxation frequency and then reach constant values until the higher-frequency infrared absorption bands. The relaxation frequency of polar ice is a few $\mathrm{kHz}$ at $-20^{\circ} \mathrm{C}$. The dielectric properties of the ice were found to be dependent on the acid and neutral-salt concentrations in the ice (Moore and others, 1989). Specifically, the high-frequency limit of conductivity $\sigma_{\infty}$, and the relaxation frequency $f_{\mathrm{r}}$ of the main dielectric dispersion depended linearly on strong acid $\left(\mathrm{HCl}, \mathrm{H}_{2} \mathrm{SO}_{4}\right.$ and $\mathrm{HNO}_{3}$ ) and neutral-salt (mainly $\mathrm{NaCl}$ ) concentrations. DEP uses a fixed set of curved electrodes spanning the length of the ice core. Usually 20 frequencies are sampled at each electrode, with a complete set of measurements taking about $20 \mathrm{minm}^{-1}$. Resolution is fixed by the width of each electrode and is typically 2$5 \mathrm{~cm}$. The resolution is limited by the need to have a minimum geometric capacitance between the electrodes of about $0.1 \mathrm{pF}$. This method has been used at $2 \mathrm{~cm}$ resolution on the entire GRIP core, and the data will be discussed elsewhere.

The new high-resolution dielectric profiling (HRDEP) system was developed to study the detailed dielectric stratigraphy at the millimetre resolution required to distinguish the thin layers in deep ice cores such as the GRIP core. The new system was designed to increase the resolution of the method, the speed required for measurement and decrease the data analysis required.

\section{METHOD}

The new system uses the same four-terminal dielectric bridge (Wayne Kerr 6425) and microcomputer (HP 85B) as described for the DEP system by Moore and Paren (1987). Four terminal measurements are made, as the bridge can then remove stray capacitance from the coaxial cables. The new HRDEP uses a different electrode system (Fig. 1). One electrode is curved as for the normal DEP, is made of aluminium foil mounted on foam and Perspex, and provides a cradle for the core to rest on during measurement. The other (LO) electrode is moved along the cut surface of a core. The LO and guard electrodes are made from thin aluminium plate mounted on a $2 \mathrm{~cm}$ thick Perspex block. Connections were made through the back of the block to a coaxial " $\mathrm{T}$ " connector where the two LO cables are connected to the LO terminals on the bridge. The $\mathrm{HI}$ electrode is connected in a similar way. Only one frequency is measured in order to speed up measurement of the core. We chose $50 \mathrm{kHz}$ as the measurement frequency because it is well above the relaxation frequency of the ice, and therefore the $50 \mathrm{kHz}$ conductivity is a good approximation to $\sigma_{\infty}$. Of course, even higher frequencies would have been better in 

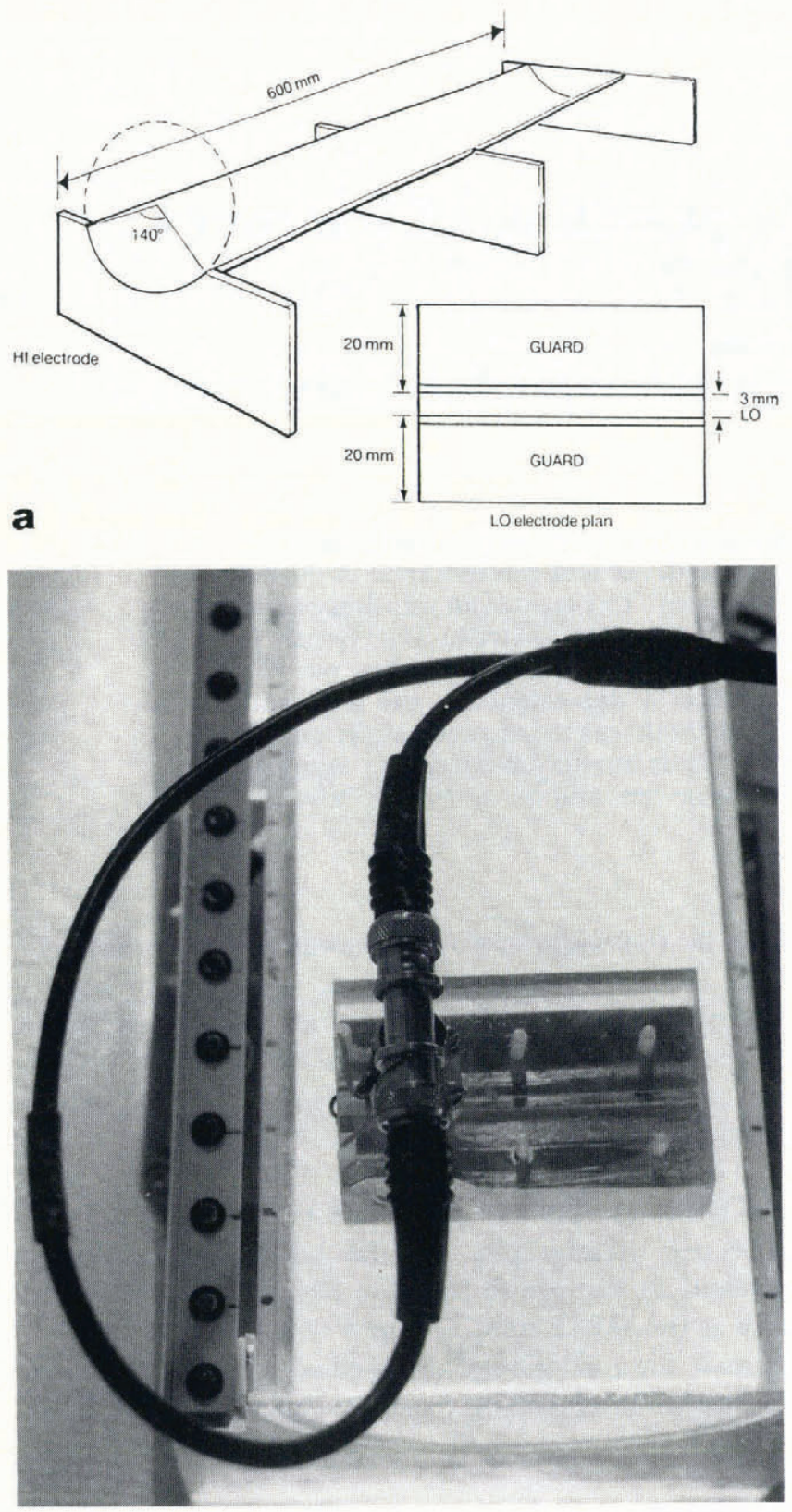

b

Fig. 1. a. Diagram of the HRDEP electrodes. The aluminium $L O$ and guard electrodes are mounted on Perspex and separated by a gap of about $1 \mathrm{~mm}$; b. Photograph showing the LO electrode, guards and connectors mounted on Perspex on top of an ice core. The HI electrode is obscured by the ice core. To the left and right of the core are marks at $2 \mathrm{~cm}$ intervals.

approximating $\sigma_{\infty}$, but the WK6425 measures frequencies above $50 \mathrm{kHz}$ with reduced resolution. Because only a single frequency is measured, there is no information on one of the dielectric parameters, $f_{\mathrm{r}}$. Acids modify the d.c. conductivity of ice, whereas salts modify the a.c. Debye dispersion; $f_{\mathrm{r}}$ is a useful parameter in separating the two processes (Moore and others, 1992). This loss of information is not a serious problem for ice from most drilling sites where either salts or acids will dominate the conductivity. At GRIP, the Holocene ice is dominated by acids and the Wisconsin ice by salts, with only small parts of the core where both salts and acids are electrically important.

The minimum area of electrode, and therefore the maximum spatial resolution that can be obtained, depends on the resolution of the dielectric bridge. For the Wayne Kerr 6425, we judge that a minimum geometric capacitance of $0.1 \mathrm{pF}$ is required. The GRIP ice core is $10 \mathrm{~cm}$ in diameter. The cores are cut longitudinally into sections leaving a flat surface at least $8 \mathrm{~cm}$ across. Measuring the dielectric properties of the core after this cut increases the geometric capacitance available because the average distance between the electrodes is reduced. Moore and Maeno (1991) showed that the geometric capacitance, $C$, of two curved electrodes is given by

$$
C=\epsilon_{0} l[\ln \tan (\pi / 4+\phi / 2)]
$$

where $\epsilon_{0}$ is the permittivity of free space $\left(8.854 \mathrm{pF} \mathrm{m}^{-1}\right), l$ is the length of the electrode and $2 \phi$ is the angle the electrodes subtend at the centre of the ice core, in this case chosen to be $140^{\circ}$ to match that in the standard DEP system. The bigger $\phi$, the larger is $C$, but the greater is the contribution from the parts of the core closest to the outside edge, where contamination introduced during drilling and handling is greatest. Notice that the width of the electrode across the core is determined by the angle $\phi$. A value for $l$ of $6 \mathrm{~mm}$ gives $C=0.1 \mathrm{pF}$. The longitudinally cut cores have a higher geometric capacitance since the average separation of the electrodes is less. Half cores would give twice the capacitance. Generally, the GRIP core was cut such that approximately half cores were available, therefore we designed the electrode with a width of $3 \mathrm{~mm}$. The GRIP ice core was cut into $55 \mathrm{~cm}$ lengths for packing; it was convenient to use these $55 \mathrm{~cm}$ lengths for the HRDEP measurements. The HI electrode ran the $55 \mathrm{~cm}$ length of the core sections (Fig. 1). The maximum speed of measurement of the bridge and microcomputer was four samples $\mathrm{s}^{-1}$. The electrode was moved across the ice surface at the rate of $1 \mathrm{~cm} \mathrm{~s}^{-1}$, giving one measurement every $2-3 \mathrm{~mm}$. The dielectric parameters given by the bridge are an average over the interval of measurement, and therefore over the length of core that the electrode moves across. The electrode is $3 \mathrm{~mm}$ wide and moves $2-3 \mathrm{~mm}$ during the measurement, therefore $5-6 \mathrm{~mm}$ of core contribute to each measurement, although thinner features should be resolved if they have a significant conductivity contrast to the surrounding ice. The resolution can be improved significantly with a faster microcomputer, increasing measurement speed. The electrode was moved by hand with the position checked by signals from the computer. In future it should be easy to record the position digitally along the core.

As with the standard DEP, the ice core could be measured inside a polythene sleeve, since at frequencies $\gg f_{\mathrm{r}}$ the conductivity of the ice inside the insulating sleeve is very close to the conductivity of the ice (Gross and others, 1980). Generally, the ice was measured directly with no insulating sleeve. Guard electrodes were used to keep the electric field from spreading beyond the edges of the electrode (Fig. 1). The guard is at the same potential as the LO electrode and, for parallel plate electrodes, should be twice as large as the separation between the electrodes (Hippel, 1954). The size of the 
guards is a compromise between the need to keep the field parallel at the LO electrode and the reduction in bridge sensitivity caused by the metal guards not being connected to the LO electrode.

The capacitance and conductance data were stored on computer. In principle, the conductivity of the ice can be estimated from the capacitance data, assuming a dielectric constant for ice. The capacitance data are not very accurate and we feel that they are not reliable enough for this approach. We have, therefore, simply produced plots of the $50 \mathrm{kHz}$ conductance.

\section{RESULTS}

Figure 2a shows the $50 \mathrm{kHz}$ HRDEP profile across a $55 \mathrm{~cm}$ section of ice core from the GRIP core at depths between 1528.45 and $1529 \mathrm{~m}$. The ice from this depth is from the Holocene and is acidic ice. Most of the ionic impurity is present as acid, with minor amounts of neutral salts. The shape of the HRDEP profile is closely reproduced, in a smoothed form, by the normal DEP $\sigma_{\infty}$ profile obtained at $2 \mathrm{~cm}$ resolution. The $\sigma_{\infty}$ profile was measured at temperatures within a few degrees of $-15^{\circ} \mathrm{C}$, and then corrected to $-15^{\circ} \mathrm{C}$ as the standard temperature. The large peak is probably a volcanic acid feature. The HRDEP conductance data are limited in resolution, producing the "quantized" level changes seen in Figure 2. The system resolution was limited by the speed at which the bridge was programmed to measure. The resolution can be improved by a factor of five by using a slower speed. This was unfortunately not done in the 1991 season owing to the use of the rather slow HP $85 \mathrm{~B}$ microcomputer.

Figure $2 b$ shows the HRDEP plot from the GRIP core at depths between 2135.65 and $2136.2 \mathrm{~m}$. This is below the Holocene/Wisconsin boundary. In Greenland, Wisconsin ice is generally alkaline with much higher levels of dust and salt than found in the Holocene ice (Herron and Langway, 1985). In comparison with Figure 2a, the response is lower. Moore and others (1989) showed that the response of $\sigma_{\infty}$ to $1 \mu \mathrm{mol}$ of acid is about seven times as great as for $1 \mu \mathrm{mol}$ of neutral salt. Even though typical concentrations of neutral salts in Wisconsin ice are much larger than those of acid in Holocene ice, they do not compensate for the neutralization of the acid. The background levels of conductance and $\sigma_{\infty}$ are not zero owing to the intrinsic conductivity of pure ice (Moore and others, 1992), expected to be $9 \mu \mathrm{S} \mathrm{m}^{-1}$ at $-15^{\circ} \mathrm{C}$. The high-frequency variations in the curve are at a period close to that found for variations in $\mathrm{Ca}$ and also the separation between visible cloudy or dusty layers in the core. The conductance cycles also thin with depth in a similar manner to modelled annual-layer thickness (for example, see Radok and others, 1982). It is unlikely that $\mathrm{Ca}$ is responsible for variations in $\sigma_{\infty}$, because the $\mathrm{Ca}$ ions or dust are unlikely to introduce lattice defects in the ice. However, the levels of sea-salt $\mathrm{Cl}$ are much increased in the Wisconsin and it is likely to follow a similar seasonal cycle to the $\mathrm{Ca}$, as both are strongly dependent on wind transport from distant sources. The high-frequency variations in the HRDEP conductance are, therefore, thought to be due to seasonal variations in the salt
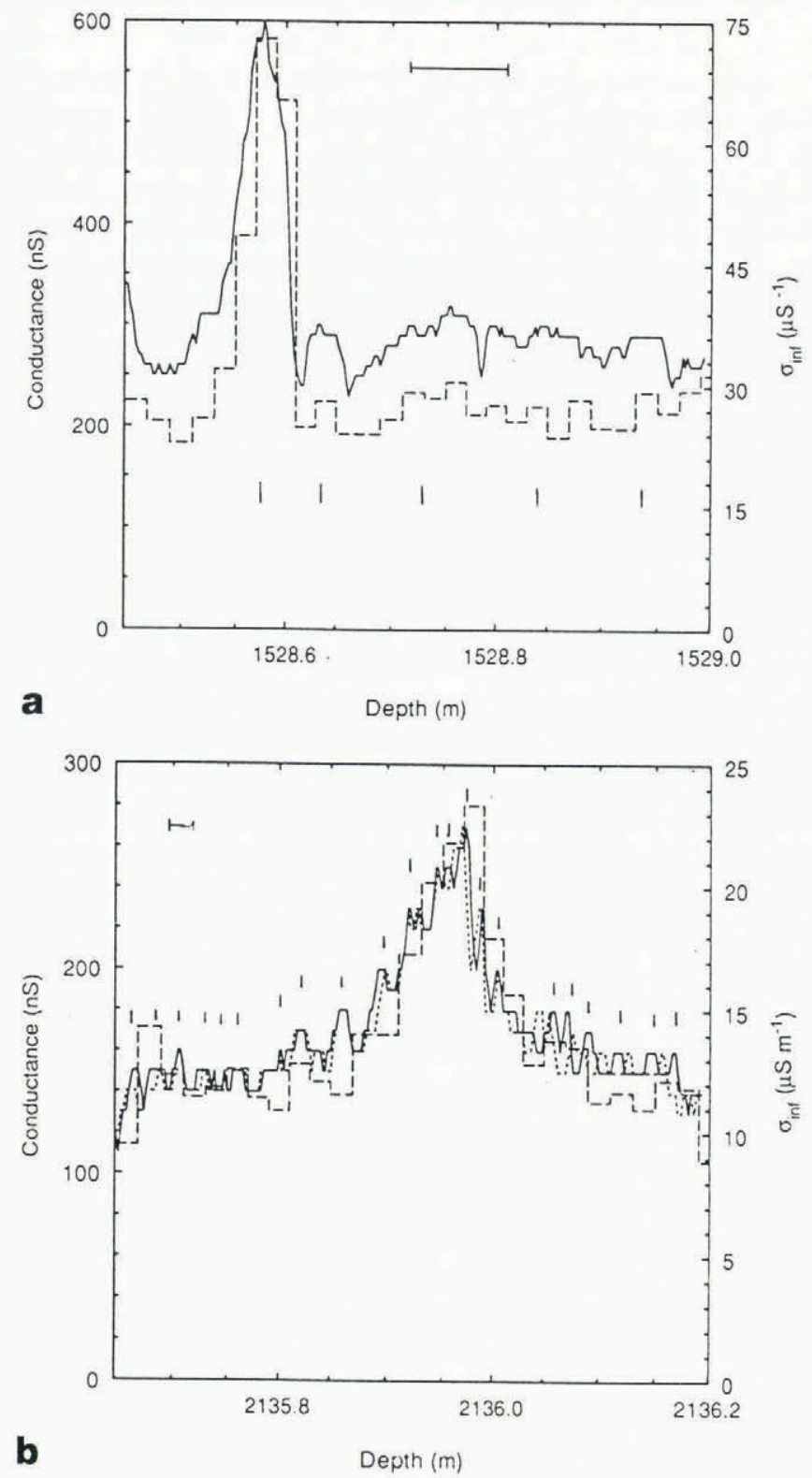

Fig. 2. a. Example of the HRDEP profile $(50 \mathrm{kHz}$ conductance; solid line) and the DEP $\sigma_{\infty}$ profile (dashed line) for a $55 \mathrm{~cm}$ section of the GRIP core from the Holocene part of the core; $b$. Two repeat HRDEP profiles (solid and dotted lines) from Wisconsin ice in a deeper part of the core, and the DEP $\sigma_{\infty}$ profile (dashed line). The two repeat runs correlate for the first part of the core, but the curves become less in agreement near the bottom end, probably due to an offset in the $x$-axis. The curves would fit much better if the dotted line was moved up the core by $1-2 \mathrm{~cm}$ in the bottom part of the plot. The horizontal line is the expected annual-layer thickness at the depths in the figures. Some annual-layer peaks are indicated. Annual cycles are not well represented over all the core lengths, but there are parts of the cores where it is possible to be confident in our delineations.

concentrations; the close agreement between the two HRDEP runs shows that the variations are quite repeatable. The two repeat runs are in agreement in the upper part of the core, but near the bottom, the two runs appear to become different. We feel that the difference is 
due to an offset in the $x$-axis, as the peaks would match well in shape and size if the dotted curve were moved up the core about $1-2 \mathrm{~cm}$ from $2136.0 \mathrm{~m}$ down. The error was due to practical difficulties in operating the system at the GRIP site, which will be solved in future operations. The normal DEP shows only broad features but the HRDEP system shows layers that are believed to be annual. Figure 2 clearly has some parts where the layers are much easier to see than in other parts. This was generally the case in the records of Wisconsin ice. However, sufficient areas of clear cycles exist to allow us to state that the system can be used to estimate the annual-layer thickness, even in the old Wisconsin ice.

\section{GONCLUSION}

The HRDEP method provides a simple, quick and detailed stratigraphic analysis tool for ice cores. The high-frequency conductivity of the ice, being determined by both acids and salts in the core, gives significant seasonal signals in the alkaline ice of the Wisconsin. The technique should have sufficient resolution to measure layers less than $1 \mathrm{~cm}$ thick. Improvements to the resolution and accuracy of the measurements are under way, and the method should prove of general use in icecore analysis.

\section{ACKNOWLEDGEMENTS}

This work is a contribution to the Greenland Ice Core Project (GRIP), a European Science Foundation programme with eight nations collaborating to drill through the central part of the Greenland ice sheet. The work would not have been possible without the great care and skill of the many drillers involved.

\section{REFERENCES}

Gross, G. W., I. C. Hayslip and R.N. Hoy. 1980. Dielectric relaxation spectrum of ice measured with linear blocking electrodes. Geophysics, 45(5), 914-927.

Herron, M. M. and C. C. Langway, Jr. 1985. Chloride, nitrate, and sulfate in the Dye 3 and Camp Century, Greenland ice cores. In Langway, C. C., Jr, H. Oeschger and W. Dansgaard, eds. Greenland ice core: geophysics, geochemistry, and the environment. Washington, DC, American Geophysical Union, 77-84. (Geophysical Monograph 33.)

Hippel, A. von. 1954. Dielectrics and waves. New York, John Wiley and Sons.

Moore, J.C. and N. Maeno. 1991. Application of the dielectric profiling technique to ice core studies. Proceedings of the NIPR Symposium on Polar Meteorology and Glaciology 4, 81-92.

Moore, J. C. and J. G. Paren. 1987. A new technique for dielectric logging of Antarctic ice cores. 7. Phys. (Paris), 48, Colloq. C1, 155-160. (Supplément au 3.)

Moore, J.C., R. Mulvaney and J.G. Paren. 1989. Dielectric stratigraphy of ice: a new technique for determining total ionic concentrations in polar ice cores. Geophys. Res. Lett., 16(10), 1177-1180.

Moore, J. C., E.W. Wolff, H. B. Clausen and C. U. Hammer. 1992. The chemical basis for the electrical stratigraphy of ice. J. Geophys. Res., 97(B2), 1887-1896.

Radok, U., R. G. Barry, D. Jenssen, R. A. Keen, G. N. Kiladis and B. McInnes. 1982. Climatic and physical characteristics of the Greenland ice sheet. Boulder, CO, University of Colorado. Cooperative Institute for Research in Environmental Sciences.

The accuracy of references in the text and in this list is the responsibility of the author, to whom queries should be addressed. 